\title{
Neighborhood Ethnic Composition and Resident Perceptions of Safety in European Countries
}

\author{
Moshe Semyonov, Tel-Aviv University and University of Illinois at Chicago
}

Anastasia Gorodzeisky, Ben-Gurion University of the Negev

Anya Glikman, Tel-Aviv University

\begin{abstract}
Employing data from the 2002 European Social Survey for 21 national representative samples, we provide the first cross-national analysis of the relations between ethnic composition of neighborhood and perception of neighborhood safety in the European context. The data reveal considerable variation both across countries and across individuals in perceived safety. Bi-level regression analysis shows that perceived safety tends to be lower in countries characterized by a high imprisonment rate and among Europeans who are physically and socially vulnerable (e.g., among women and elderly people, and among populations of low income and low education). Net of individual-level and country-level attributes, the analysis shows that perceived safety is lowest in neighborhoods mostly populated by non-European ethnic minorities and highest in neighborhoods mostly populated by Europeans. The effect of ethnic composition of neighborhood on perceived safety holds even after controlling for previous personal exposure to crime and views toward minorities' impact on crime. We discuss the results in comparison to findings in the United States and in the light of theory in order to delineate the ways that views and perceptions about places are formed and shaped. Keywords: ethnic composition; neighborhood safety; Europe; fear of crime; immigration.
\end{abstract}

The increasing literature on ethnic residential segregation has repeatedly demonstrated that spatial segregation has significant consequences for living conditions and for quality of life (e.g., Collins and Williams 1999; Massey and Denton 1993; Peterson and Krivo 1993; Walton 2009; Wight et al. 2010). Members of ethnic minorities tend to reside in poor neighborhoods, where social and community services are scarce and crime and violence are widespread. By contrast, members of the majority population tend to dwell in affluent and prestigious communities in which social and cultural amenities are abundant, living conditions are pleasant, and criminal activity and exposure to violence are low. It is highly possible, therefore, that the reluctance of the majority population to share residential space with ethnic minorities does not only stem from prejudice, but may also be attributed to fear of victimization and a desire to secure greater personal safety (e.g., Harris 1999; Quillian and Pager 2001).

In this article, we focus on the relationship between perceived ethnic composition of neighborhood and perceived neighborhood safety in Europe. Whereas the relations between racial composition of neighborhoods and fear of crime, or perceived safety, have been extensively studied in the United States (Chiricos, Hogan, and Gertz 1997; Chiricos, McEntire, and Gertz 2001; Liska, Lawrence, and Sanchirico 1982; Quillian and Pager 2001), as far as we are aware, the

This article was presented at the annual meeting of the American Society of Criminology, November 2011, Washington DC. The authors wish to thank Yitchak Haberfeld, William P. Bridges, Anthony M. Orum, anonymous reviewers, and the editor of Social Problems for helpful comments and suggestions. Direct correspondence to: Moshe Semyonov, Department of Sociology, Tel Aviv University, PO Box 39040, Tel Aviv 69978, Israel. E-mail address: moshes@post.tau.ac.il.

Social Problems, Vol. 59, Issue 1, pp. 117-135, ISSN 0037-7791, electronic ISSN 1533-8533. @ 2012 by Society for the Study of Social Problems, Inc. All rights reserved. Please direct all requests for permission to photocopy or reproduce article content through the University of California Press's Rights and Permissions website at www.ucpressjournals.com/reprintinfo/asp. DOI: 10.1525/sp.2012.59.1.117. 
subject has not yet been explored in the context of European societies. Our goal, however, goes far beyond the replication of previous studies in the European context. We aim here to make a threefold contribution: First, we provide for the first time a systematic cross-national analysis of the relationships between perceived ethnic composition of neighborhood and perceived neighborhood safety in the European context. Second, we examine the impact of both individual-level attributes (i.e., socioeconomic and demographic) and country-level structural characteristics (i.e., crime rate and the proportion of the minority population residing in the country) on variations in perceived neighborhood safety. Third, we examine the extent to which the relationship between perceived ethnic composition of neighborhood and perceived neighborhood safety is influenced by personal exposure to crime and by beliefs about the impact that ethnic minorities have on crime. By so doing, we will not only be able to contribute to empirical knowledge on European societies, but also to delineate the ways in which views and perceptions about ethnic neighborhoods and personal safety are formed and shaped.

\section{Theoretical Considerations and Previous Research}

Social scientists have long suggested that the ethnic and racial composition of particular places affects the feelings and attitudes of the majority toward members of the minority group population. According to the "visibility" or "threat" theoretical model (e.g., Blalock 1967; Blumer 1958), an increase in the relative size of a minority population is likely to increase hostility, negative sentiment, and prejudice toward members of the minority population. This is so because the minority population is often viewed by members of the majority as being potential competitors for scarce resources, rewards, and prerogatives, and consequently as a threat to their way of life. Any increase in the relative size of the minority population is, therefore, likely to increase the perception of threat. Perceived threat, in turn, is likely to promote hostility, antagonism, and negative sentiment towards the minority population, as was most succinctly summarized by Lincoln Quillian (1995): "The greater the sense of threat to their prerogatives, the more likely are members of the dominant group to express prejudice against threatening outsiders" (p. 588).

The "threat" thesis has gained considerable support through a series of studies that demonstrate that anti-minority attitudes tend to increase with the relative proportion of the minority population. For example, Marylee C. Taylor (1998) and Mark A. Fossett and K. Jill Kiecolt (1989) show that discriminatory attitudes towards blacks in the United States tend to be more pronounced in places where blacks constitute a larger proportion of the population. Likewise, a large body of comparative studies across European countries reveals that antiimmigrant sentiment is likely to rise with the proportion of non-Europeans residing in the country (e.g., Quillian 1995; Scheepers, Gijberts, and Conders 2002; Semyonov, Raijman, and Gorodzeisky 2006). Notwithstanding the impact of size (as a structural source of competitive threat) on negative attitudes toward minority populations, several studies have shown that the perceived size of the minority population is more likely to increase anti-minority sentiment than the actual size (Alba, Rumbaut, and Marotz 2005; Gallagher 2003; Semyonov et al. 2004 for Germany; Semyonov, Raijman, and Gorodzeisky 2008 for Europe; Sigelman and Niemi 2001 for the United States). The more inflated the perceived size of the minority population the more pronounced are anti-minority sentiments.

The logic embodied in the "threat" theoretical model leads us to expect that an increase in the presence of the out-group population (e.g., ethnic minority, immigrants) in an area would not only lead to a rise in antagonism, hostility, and prejudice toward the out-group population but would also promote fear of victimization (or decrease the in-group's sense of personal safety). In fact, studies have consistently found that perceptions of neighborhood safety are highly related to the racial composition of the locality. More specifically, a high concentration of blacks (especially of black men) and of Hispanic immigrants in American cities has been shown to increase the fear 
of criminal victimization and to decrease the sense of personal safety (Chiricos et al. 1997; Eitle and Taylor 2008; Liska et al. 1982; Quillian and Pager 2001). For example, Arthur Stinchcombe and colleagues (1980) and Gertrud Moeller (1989), who based their analyses on survey data, found that proximity to a black neighborhood is likely to increase fear of criminal victimization. That is, individuals who state that they live in a black neighborhood are more likely to express fear than others. Likewise, Ted Chiricos, Renee McEntire, and Marc Gertz (2001) reported a strong association between perceived racial composition of neighborhood and fear of victimization. More specifically, Chiricos and colleagues (2001) showed that perceived risk of victimization among whites tends to rise with the perception that either blacks or Hispanics live in close proximity to them.

Researchers who used census data to examine the relations between (actual) racial composition of the neighborhood and respondents' fear of crime (e.g., Chiricos et al. 1997; Liska et al. 1982; Quillian and Pager 2001) found that fear is likely to rise with the proportion of ethnic and racial minorities in the locality. For example, Allen E. Liska, Joseph J. Lawrence, and Andrew Sanchirico (1982) demonstrated that fear of crime tends to rise with the relative size of the black population in a metropolitan area, and David Eitle and John Taylor (2008) found that the proportion of Hispanics living in a neighborhood is a contextual predictor of fear of criminal

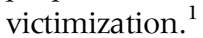

It should be noted that the impact of ethnic composition of place on fear of crime and on perceptions of safety is likely to hold even after taking into consideration variations in actual crime rates across communities. For example, Liska and colleagues (1982) found that fear tends to be higher in metropolitan areas with a higher proportion of blacks, even after controlling for measures of crime rates. They suggested, therefore, that the greater fear of crime among whites residing in "blacker" metropolitan areas might result from cultural stereotypes. Along the same line of logic, Quillian and Devah Pager (2001) investigated the relations between neighborhood racial composition and residents' perceptions regarding crime rate in the neighborhood. They found the percentage of young black men to be positively associated with perception of crime level after controlling for actual crime rates (and several other neighborhood characteristics). Apparently, contextual stereotyping of neighborhoods (expressed in term of racial or ethnic coding) may play a major role in driving up fear of criminal victimization.

Notwithstanding the significant impact of ethnic composition of neighborhood on fear of crime and on sense of safety, the literature also highlights a series of individual-level attributes that affect sense of safety over and above neighborhood context. Specifically, the literature suggests that regardless of place of residence, sense of safety is less pronounced among socially and physically vulnerable persons for crime (e.g., De Donder, Verte, and Messelis 2005; Pain 2000; Sutton and Farrall 2005; Whitley and Prince 2005). Thus, women and the elderly, who are physically more vulnerable, might express lower sense of safety than men or young people.

Likewise, the literature suggests that previous personal exposure to crime is likely to increase fear of crime and to decrease sense of personal safety. That is, people who have been victimized by crime-either directly or vicariously-are more likely to express a greater level of fear (Bursik and Grasmick 1993; Gray, Jackson, and Farrall 2011; Skogan 1990; Taylor 1995; Tseloni and Zarafonitou 2008). Therefore, in the analysis that follows, we will control for such individuallevel attributes (e.g., socioeconomic, demographic, and exposure to crime) when studying the relations between perceived ethnic composition of the neighborhood and sense of neighborhood safety.

1. It is important to note that the effects of racial or ethnic composition on fear of victimization are context and measure dependent (e.g., Thompson, Bankston, and St. Pierre 1992). For example, Stults and Baumer (2007) found that while a high percentage of blacks is likely to increase fear of victimization, a high percentage of Hispanics has no such effect (see also Quillian and Pager 2001). In Miami-Dade County, however, the percentage of Hispanics (but not the percentage of blacks) proved to be the critical factor for respondents' sense of fear (Eitle and Taylor 2008). 
Following the logic embodied in the theoretical outset of this article, we expect perceived ethnic composition of neighborhood to affect fear of victimization (i.e., sense of neighborhood safety) in the same way it affects attitudes toward ethnic minorities; the larger the perceived proportion of ethnic minorities residing in a given neighborhood the more pronounced are the negative attitudes, and the less pronounced is the sense of neighborhood safety. However, we expect the impact of neighborhood ethnic composition on sense of safety to extend over and above the impact of attitudes toward ethnic minorities. Likewise, we expect the effect of perceived neighborhood composition on sense of safety to extend over and above the effect of exposure to criminal victimization and physical and social vulnerability. By testing these hypotheses, we will not only be able to examine some of the consequences of ethnic residential segregation in European countries, but also to better understand the social mechanisms underlying the relations between perceived ethnic composition of the neighborhood and sense of safety. Before proceeding with the data analysis, however, we will present a brief review of the European context.

\section{The European Context: Immigration, Residential Segregation, and Fear of Crime}

Throughout the second half of the twentieth century, immigrants have arrived in European countries in ever-increasing numbers. As Europe became home to millions of overseas labor migrants, guest workers, ex-colonials, immigrants, and refugees, the ethnic fabric of many European cities dramatically changed (Castles and Miller 1993; Lahav 2004; Musterd 2005; Pettigrew 1998; Thomson and Crul 2007). For example, French and Belgian cities have become home to North Africans and sub-Sahara Africans, while Greek towns have become a destination for Albanians and Macedonians. English cities have been populated by black Caribbean, Indian, Pakistani, and Bangladeshi populations, while German cities were inhabited by Turks and Yugoslavians. Cities in Holland attracted Surinamese, Indonesians, and Moroccans, whereas Portugal accepted African and Southeast Asian immigrants (Musterd 2005; Pettigrew 1998).

The influx of ethnic groups into Europe has created a variety of new ethnic communities and ethnic neighborhoods in most European cities. The growing body of research on the topic suggests that ethnic residential segregation across European cities is substantial, widespread, and for the most part, growing (e.g., Karsten et al. 2006; Logan 2006; Malheiros and Vala 2004; Musterd 2005; Musterd, Ostendorf, and Breebaart 1998; Peach 1997, 2005; Van Kempen and Van Weesep 1997). Currently, most metropolitan centers in Europe are characterized by distinctly segregated ethnic neighborhoods that are viewed by native Europeans as the least desirable place of residence (Semyonov, Glikman, and Krysan 2007). Nevertheless, it is not clear from the literature whether and to what extent residence in ethnic neighborhoods in Europe is associated with greater fear of crime and lower sense of safety.

To date, most of the research on fear of crime in European societies has focused on factors underlying fear of crime in single countries such as the United Kingdom (e.g., Gray et al. 2008; 2011), Belgium (De Donder et al. 2005), and Greece (Tseloni and Zarafonitou 2008). These studies reveal that fear is more pronounced among the poor, the elderly, and the less educated. Fear of criminal victimization is also more evident among women and among previous victims of crime (De Donder et al. 2005; Tseloni and Zarafonitou 2008) as well as among residents of neighborhoods characterized by a high level of social disorder and a low level of social involvement (De Donder et al. 2005; Gray et al. 2011; Jackson 2004; Jackson and Bradford 2009).

Cross-national comparative research on fear of crime across European countries demonstrates that fear of crime is highest in Mediterranean, southern European countries, in the United Kingdom, and in Eastern European countries, and lowest in the Scandinavian countries (European Opinion Research Group 2003; Mayhew and van Dijk 1997; Nieuwbeerta 2004; van Dijk, van Kesteren and Smit 2008; van Kesteren, Mayhew, and Nieuwbeerta 2000). In a study 
of 22 European countries, Bobby Reese (2009) found that people in general, and victims of crime in particular, are less fearful of crime in "high-crime rate" countries than in "low-crime rate countries." ${ }^{2}$ Recent research by Dina Hummelsheim and colleagues (2011), conducted on data from 23 European countries, suggests that the country specific organization of the welfare state exerts an impact on fear of crime. Specifically, higher social expenditures and a higher degree of decommodification of social welfare policy are accompanied by lower level of fear of crime.

Surprisingly, no research to date, as far as we are aware, has examined within the context of European societies whether and to what extent fear of crime is associated with the presence of immigrants in the neighborhood. Furthermore, to the best of our knowledge there are no studies that examine the effect of presence of ethnic and racial minorities on sense of neighborhood safety in Europe. This neglect is especially unfortunate in light of the fact that immigrants are often blamed for a rise in crime, violence, social ills, and various other pathologies in Europe (e.g., Ceobanu 201 1; Pettigrew 1998; Semyonov et al. 2008). Thus, before proceeding with the analysis we use data from the 2002 European Social Survey (Jowell 2003) to provide a descriptive overview of views regarding immigrants' impact on crime ${ }^{3}$ across European countries.

In Figure 1, we display average public beliefs regarding the impact that the presence of foreign residents has on crime across 21 countries, measured on an 11 -point scale $(0=$ positive to $10=$ negative). The figure reveals that on average and without exceptions, attitudes were negative in all countries (mean value across Europe is 6.78). ${ }^{4}$ Yet, some variation across countries is also observed. Respondents in Ireland, Slovenia, and the United Kingdom expressed quite moderate negative views, while respondents in the Czech Republic, Hungary, and Norway express more extreme views. However, the most negative views were expressed in Greece, where the average level of negative attitudes toward foreigners' impact on crime is particularly high, both in relative and absolute terms (average value is 8.2). ${ }^{5}$

The cross-national variation in negative views toward immigrants with regard to crime, however, cannot be explained either by crime rate at the country level or by an individual's previous exposure to crime. Alin Ceobanu (2011), who examined public attitudes toward immigrants' impact on crime in 21 countries (using data from 2002 European Social Survey), found that while perceptions of immigrants' impact on crime problems are unaffected by personal experience with crime and by contextual measures of crime, they are affected by size of non-European immigrant population (i.e., negative views toward immigrants' impact on crime are more pronounced in countries with larger proportions of foreign population). Ceobanu concluded that Europeans' attitudes regarding immigrants' impact on crime are related to fear of immigrants rather than fear of crime, and can be viewed as another form of prejudice against immigrants. It is also worth noting that Europeans' attitudes toward foreigners are more negative with regard to crime than with regard to any other social sphere (e.g., economy, employment, culture, welfare, education; see Semyonov et al. 2008).

2. However, these findings should be interpreted with caution in the light of the author's suggestion "crime rate may not represent the actual rate in a given country" (Reese 2009:64).

3. Later in the analysis we employ data from the European Social Survey to examine the extent to which the ethnic composition of the neighborhood affects fear of victimization or sense of safety. For detailed information on the European Social Survey see Jowell and associates (2003). Description of the data for the current study's analysis is provided in the next section of this article: "Data and Variables."

4. Data taken from Eurobarometer Surveys in 1988 (Survey 30; see Reif and Melich 1992) and 2000 (Survey 53; see Hartung 2002) on a closely related measure (i.e., "The presence of foreigners is one of the causes of delinquency and violence") show that the negative attitudes regarding immigrants' impact on crime had increased by a three-fold factor in 12 years. Specifically, in 1988, only 15 percent of European citizens had indicated that the presence of foreigners was considered a source of delinquency and violence. By 2000, however, the percentage of Europeans who viewed foreigners as a source of delinquency and violence had risen to 50.

5. Tseloni and Zarafonitou (2008) found that about a quarter of Greeks residing in Athens attributed fear of crime to the presence of "many foreigners" in their neighborhood. 


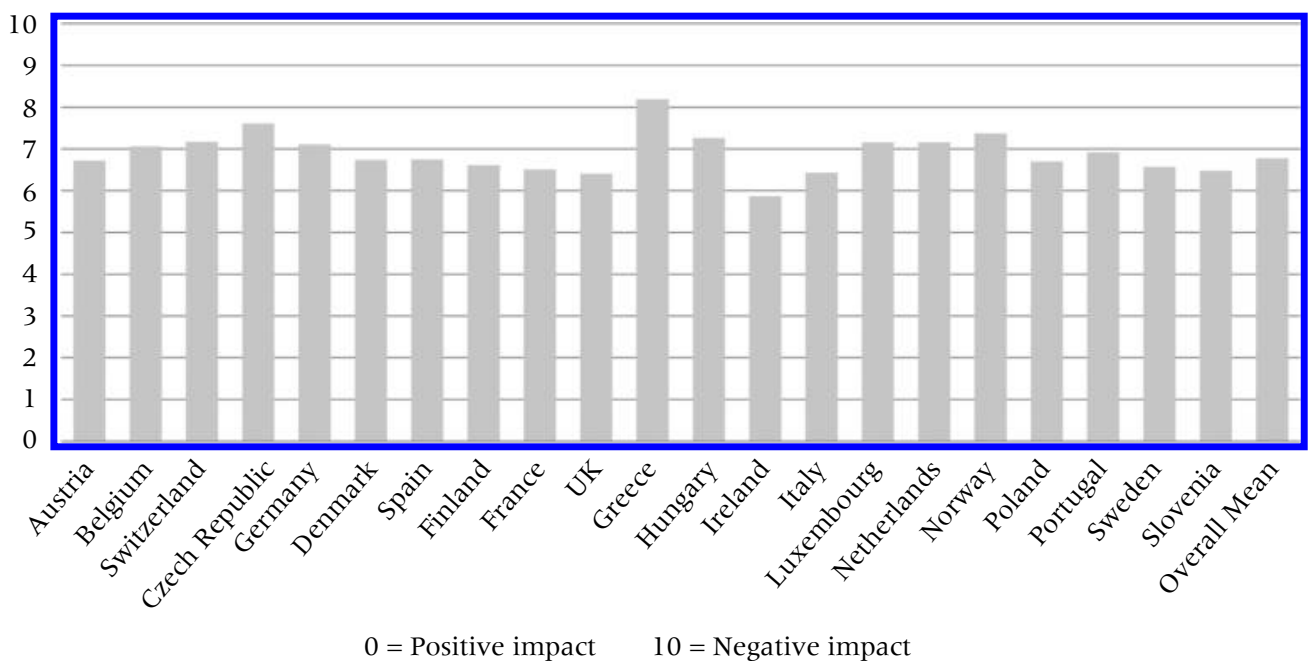

Figure 1 - Views of the Impact Foreigners Exert on Crime (Mean Response) Source: Jewell 2003

The belief that immigrants increase crime and violence is premised on the assumption that immigrants are more likely to engage in criminal activities than natives (Calavita 2003; Ceobanu 2011). However, Ruben G. Rumbaut and Walter A. Ewing (2007) argue that fear of criminal activity by immigrants is inflated and is often fueled by anecdotal reports in the mass media. Several empirical studies in the United States reveal that immigration rates and crime rates are not strongly associated (e.g., Mears 2001; Ouesy and Kurbin 2009) and studies in Europe (e.g., Tonry 1997; Yeager 1997) found that many immigrant groups have lower propensities for crime than natives. However, a recent comparative study of immigration and crime in European countries (Solivetti 2010 ) finds disproportionally high rates of nonnationals within the prison population, even after taking into account the greater share of young adults among nonnational populations and the presence of clandestine immigrants. At the same time, the author finds no relations between variations in the percentage of immigrants and variations in the rates of criminality in the host country, challenging "the popular opinion according to which immigrants in general, and some national groups in particular, are crime-prone" (Solivetti 2010:165).

Nonetheless, the popular and widespread perception that immigrants are a source of crime and violence (whether evidence based or not), coupled with a relatively high level of spatial segregation, has significant consequences for the perception that neighborhoods populated by ethnic minorities are dangerous and unsafe. Indeed, based on the knowledge accumulated by studies on attitudes toward immigrants and ethnic minorities and on their impact on crime, we expect Europeans to associate ethnic composition of neighborhood with criminal activity. More specifically, we expect Europeans living in ethnic neighborhoods to express a greater sense of insecurity than Europeans who reside in all-European neighborhoods.

\section{Data and Variables}

Data for the present study were obtained from the first round of the European Social Survey (ESS), conducted in 2002 in 21 European countries (Jowell 2003). The data provide, in addition to the sociodemographic and economic characteristics of respondents, facts about perceived ethnic 
composition of the neighborhoods as well as a variety of information on attitudes, perceptions and beliefs, and previous exposure to crime. Despite availability of four rounds of the European Social Surveys, the present analysis relies on the 2002 survey because only in this survey was a question about perceived ethnic composition of neighborhood asked. Data were collected through face-toface interviews with nationally representative samples (age 15 and older). The current research was restricted to respondents who were born in Europe, (i.e., native Europeans), and yielded a sample of 34,458 persons. $^{6}$

The dependent variable - perceived neighborhood safety—was constructed as a dummy variable by collapsing responses (on a scale from 1 to 4 ) to the following question: "How safe do you-or would you-feel walking alone in this area after dark?" into two categories of safety: respondents who feel unsafe and respondents who feel safe in the neighborhood. The data set provides us with only one measured item that captures perceived neighborhood safety. We acknowledge that a single item measure is less capable of capturing complex social phenomena than multi-item measures and may suffer from possible reliability issues. However, the measure is theoretically relevant and is based on a straightforward question that does not raise the typical problems of meaning and interpretation that generally accompany cross-national attitudinal research (Poortinga 1989). ${ }^{7}$

The independent variable in the present analysis (used as the major predictor of perceived neighborhood safety) is self-reported perceived ethnic composition of neighborhood of residence. ${ }^{8}$ The variable is based on the distinction among three types of neighborhoods: all-European (reference category), mixed neighborhood, and primarily ethnic neighborhood. Respondents were asked the following question: "How would you describe the area where you currently live? An area where: almost nobody is of a different race or ethnic group from most [country] people [hereafter "native-European neighborhoods"]; some people are of a different race or ethnic group from most [country] people [hereafter "mixed neighborhoods"]; or many people are of a different race or ethnic group?" (hereafter, "ethnic neighborhoods"). ${ }^{\text {? }}$

A series of individual-level sociodemographic characteristics, associated with social and physical vulnerability, were included in the analysis (mostly as control variables). They are: age (in years), gender $($ men $=1)$, subjective income (insufficient $=1$ ), education (in formal years). Marital status (married $=1$ ) and urban-rural distinction (rural $=1$ ) were also included as controls because unmarried people are more likely to be socially isolated (Toseland 1982) and residents of urban areas are more likely to be exposed to crime. In addition, previous exposure to crime (or personal experience with criminal victimization) and views about minorities' impact on crime were introduced to the set of independent variables. Previous exposure to crime is defined by the distinction between respondents who identify themselves (or a member of their household) as a victim of a burglary or assault in the last five years and others. Views regarding foreigners' impact on the crime in the country were measured on an 11-point scale by respondents' perceptions of the impact that foreigners have on their country's crime. ${ }^{10}$

Two country-level contextual characteristics were used in the present analysis to capture variations at the country level that can affect sense of safety. These are: size of the non-European population and crime problem. Size of the non-European population residing in the country was

6. For a detailed description of the sampling procedures and construction of variables see the ESS website (http://ess. nsd.uib.no/ess/roundl/).

7. In addition, the same single-item indicator of perceived neighborhood safety was used in previous studies on the topic (e.g., Hummelsheim et al. 2011; Rountree and Land 1996; Stults and Baumer 2007).

8. The possibility that perceived safety may affect perceived ethnic composition of neighborhood cannot be rejected outright. Perceptions can be interdependent. The available data do not enable us to examine the causal relationships between these two variables, and the issue is therefore beyond the scope of this analysis. The theoretical model discussed in this article operates under the premise that ethnic composition of the neighborhood exerts an effect on perceptions of safety.

9. Lahav (2004) and others have suggested that non-European residents are more noticeable and more visible than European immigrants (due to phenotype, dress-code, etc). Thus, their growing presence in a locality is more likely to invoke a sense of threat than that of other immigrants. It is reasonable to assume, therefore, that Europeans refer to non-European ethnic minorities when responding to questionnaire items on immigrants and ethnic minorities.

10. This single item is highly related to other indicators of prejudice (Ceobanu 2011; Semyonov et al. 2008). 
obtained from Eurostat publications for the years 2000 and 2001 and is defined by the proportion of non-Europeans residing in the country (Eurostat 2003). ${ }^{11}$ Previous studies have consistently demonstrated that anti-foreigner sentiment is likely to rise with the size of the non-European population (e.g., Quillian 1995; Scheepers et al. 2002; Semyonov et al. 2006). A country's crime problem can be affected by several factors (e.g., different legal and criminal justice systems, rates at which crimes are reported to and recorded by the police, and differences in rules and regulations). Similar to previous studies (e.g., Ceobanu 2011) we use imprisonment rate as an indicator of country's crime problem, mainly because imprisonment rate is considered to be more suitable for cross-national research than other measures and because it is less sensitive to subjective interpretations and more comparable across countries (Eurostat 2009:11). ${ }^{12}$ The number of prisoners per 100,000 persons residing in the country was obtained from the OECD Factbook (OECD 2008). We expect perceived neighborhood safety to be lower in countries characterized by a high imprisonment rate. ${ }^{13}$ The sources, definition, detailed wording, and statistical values for all variables are provided in Appendix A.

\section{Analysis and Findings}

\section{Explaining Variations in Perceived Neighborhood Safety}

The first question that this analysis seeks to address is whether perceived safety in neighborhood of residence is associated with the perceived ethnic composition of the neighborhood. That is, whether the sense of safety is highest in the all-European neighborhoods and lowest in the ethnic neighborhoods. Figure 2 displays the percentage of respondents who feel safe in their neighborhood across three types of neighborhoods (classified by perceived ethnic composition of residents) in the 21 European countries. The data reveal considerable variation across countries in the level of perceived neighborhood safety. That is, level of perceived safety is lowest in the Czech Republic, the United Kingdom, Greece, and Portugal, and highest in Norway, Denmark, Slovenia, and Austria.

However, with only one minor exception, the data reveal a uniform pattern of the relation between perceived ethnic composition of neighborhood and perceived neighborhood safety; in all countries, except for Ireland, the proportion of residents who define their neighborhood as safe is lowest in ethnic neighborhoods (where most residents are non-European ethnic minorities) and

11. The percentage of non-Europeans is considered to be a better proxy of the size of the foreign population than the percentage of all foreigners; this measure has been repeatedly used in previous studies on public reactions to immigration and thus permits comparison with the results of this body of research (e.g., Coenders, Gijsberts, and Scheepers 2004; Quillian 1995; Scheepers et al. 2002; Semyonov et al. 2006). The data for the percentage of non-EU foreigners were obtained from Eurostat-a recognized international institution with high-quality professional standards for comparative analysis (Coenders et al. 2004).

12. We repeated the analysis (for the sake of reliability) using country-level homicide rate as a second-level variable (measured by number of intentional homicides per 100,000 persons obtained from the European Sourcebook of Crime and Criminal Justice Statistics [Council of Europe 2003]). The effect of homicide rate on perception of neighborhood safety was not significant. It should be also noted that inclusion of homicide rate (instead of imprisonment rate) in the model did not alter the results in any substantive way.

13. It should be noted that several American researchers viewed imprisonment rate as an outcome of minority composition and of fear of crime (e.g., Stults and Baumer 2007; Sutton 2004), suggesting that the growth in the relative size of minority groups increases the sense of threat among members of the majority population, which leads, in turn, to a high arrest rate, a high imprisonment rate, and a large police force. Extending this logic to Europe, one could argue that a higher percentage of a foreign population in a specific European country will be accompanied by a higher imprisonment rate. In order to test this possibility, we estimated the correlation between size of foreign population and imprisonment rate across 21 European countries. The correlation between the percentage of non-European residents and the imprisonment rate is not statistically significant, and is in fact negative $(-.3, p>.05)$, hence dismissing the concern that perception of safety may mediate the effect of the proportion of the foreign population on imprisonment rate in Europe. In line with our aforementioned result, a recent comparative study of immigration and crime rates in all of the main European countries also finds that "In Europe, there is no relation at all between incarceration rates and nonnational population" (Solivetti 2010:118). 


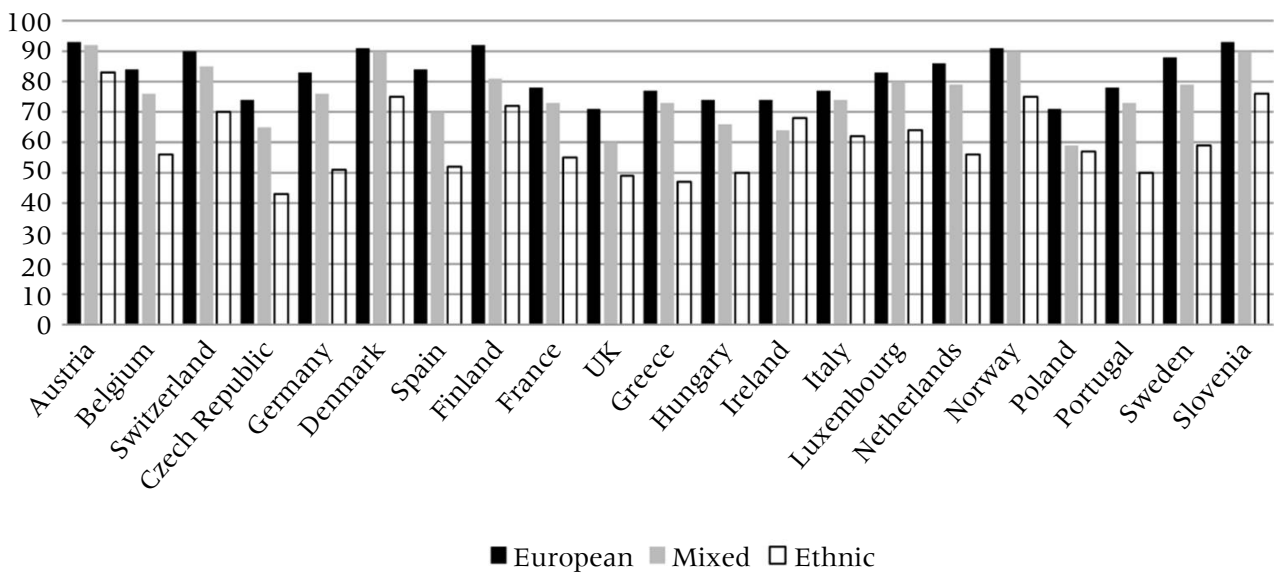

Figure 2 - Percentage of Respondents Who Perceive their Neighborhood as Safe by Type of Neighborhood Source: Jewell 2003

highest in all-European neighborhoods (where the overwhelming majority of residents are native Europeans). In Ireland, however, the percentage of respondents who feel safe in their neighborhood is lowest in mixed neighborhoods (and slightly lower than the percentage in the ethnic neighborhoods). We suspect that the "Irish anomaly" can be attributed to the unique nature of violence in Ireland, where sense of safety might be driven more by fear of political violence than by fear of conventional crime. ${ }^{14}$

Whereas the descriptive figures provide us with a useful and quite informative overview of the relations between perceived ethnic composition of neighborhood and perceived neighborhood safety, they do not directly examine the net impact of neighborhood context on perception of neighborhood safety. Nor do they shed light on the sources of such perceptions. Since countries differ not only in "perception of safety" levels but also in their structural characteristics (i.e., crime problems, percentage of non-Europeans), as well as in the sociodemographic composition of their populations, it is not clear whether the association between the perceived ethnic composition of a neighborhood and perceived neighborhood safety is attributable to country-specific structural characteristics or due to differences in the characteristics of populations across countries. For example, it is not clear whether the association between the perceived ethnic composition of the neighborhood and perceived safety is attributable to prevalence of crime and presence of ethnic minorities across countries, or whether it is due to different distributions of individuals across neighborhoods and countries. Thus, in order to examine the extent to which individual, neighborhood, and country-level structural characteristics affect perceived neighborhood safety, we estimated a series of hierarchical logistic model (HGLM) regression equations predicting perception of safety while taking into consideration cross-country variations in both the composition of the populations and country characteristics. ${ }^{15}$

In Table 1, we display coefficient estimates of three HGLM regression equations that are based on 34,458 individual observations nested in 21 countries. In Model 1 we predict the odds of

14. In addition, researchers show that while Irish people are highly concerned with crime, they are much less concerned with the issue of immigration. It seems that a pervasive sense of immigrant threat has yet to emerge in Ireland (Messina 2009).

15. HGLM bi-level regression procedure is a statistical procedure that is considered most appropriate for analysis of samples in which individuals (first level) are nested in countries (second level), because it allows estimation of country-level effects while variation in individual-level characteristics are controlled (and vice versa). 


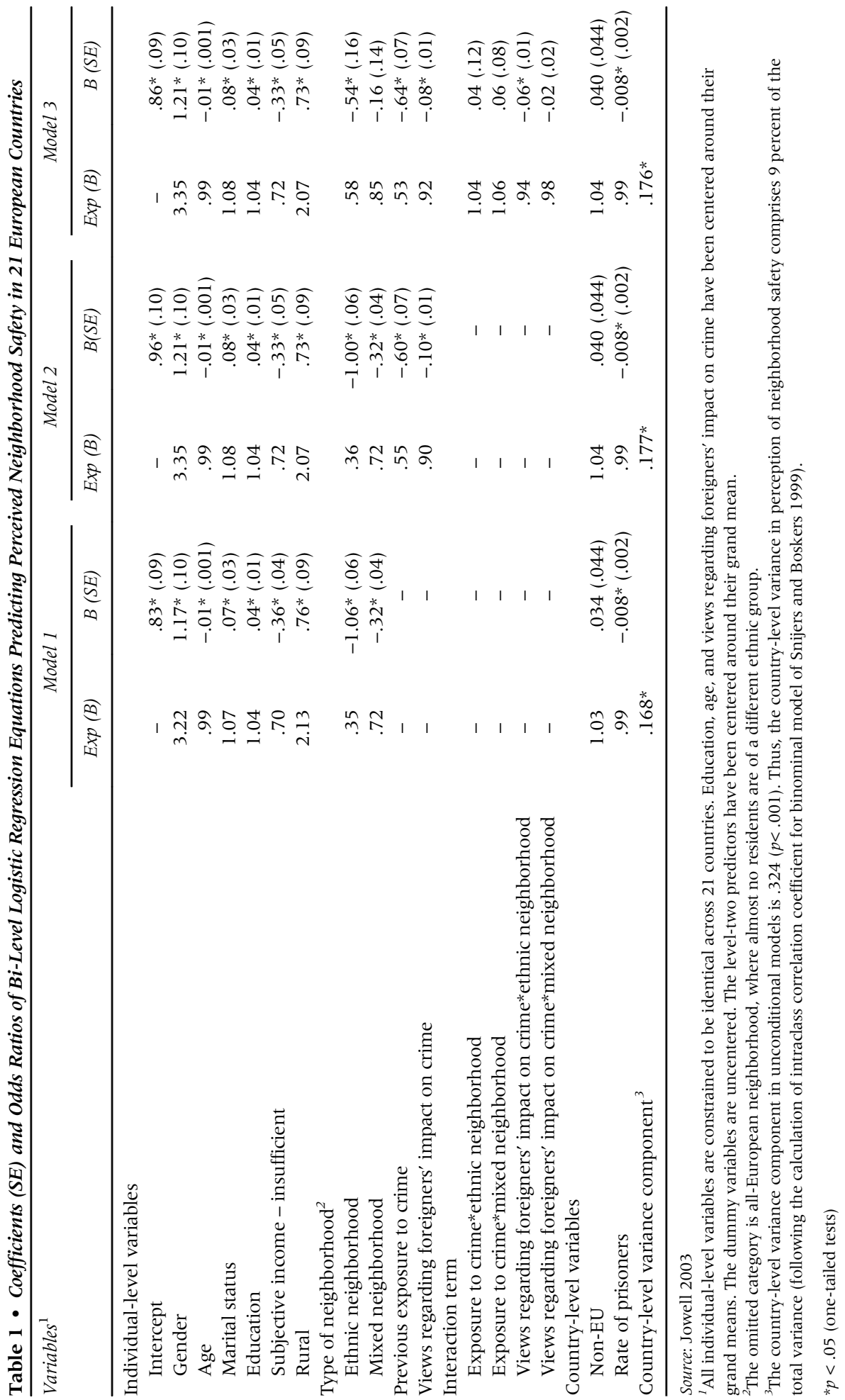


feeling safe in the neighborhood as a function of a series of dummy variables representing perceived ethnic composition of neighborhood and sociodemographic attributes (as individuallevel variables) plus percentage of non-Europeans and imprisonment rate (as two country-level variables). In Model 2 we add recent exposure to crime and views regarding foreigners' impact on crime as two individual-level variables. In Model 3 we include interaction terms between type of neighborhood and exposure to crime and between type of neighborhood and views regarding foreigners' impact on crime, in order to examine whether the impact that exposure to crime and views regarding foreigners' impact on crime has on sense of safety differs across neighborhood types. ${ }^{16}$

The data displayed in Table 1 reveal considerable variation in sense of neighborhood safety both across individuals and countries. The findings strongly support the hypothesis that sense of neighborhood safety is highly dependent on the perceived ethnic composition of the neighborhood. Specifically, and consistent with theoretical expectations, the data reveal that the odds of feeling safe in a neighborhood are lowest for residents of ethnic neighborhoods and highest for residents of all-European neighborhoods, even after controlling for individual's sociodemographic attributes. For example, in Model 1 the odds of feeling safe for residents of ethnic neighborhood are .35 times the odds of European neighborhood residents, as demonstrated by the negative and significant coefficient: $b=-1.06$ (exp $(-1.06)=.35$ ). The odds of feeling safe for residents of mixed neighborhood are .72 (exp (-.32)) times the odds of European neighborhood residents. Likewise, in all other equations, the values of the coefficients for the ethnic neighborhood and for the mixed neighborhood indicate that even after controlling for individuals' sociodemographic attributes, previous exposure to crime, and views regarding foreigners' impact on crime-as well as for variations in a country's non-European percentage and imprisonment rate-the sense of safety is lowest among residents of ethnic neighborhoods and highest among residents of European neighborhoods.

Perception of neighborhood safety is also influenced by individual-level sociodemographic characteristics. In all equations, the odds of feeling safe while walking alone in the neighborhood after dark are significantly lower among women and those who perceive their own income as insufficient; they tend to decrease with age but to increase with education and to be higher among those residing in rural places.

At the country level, perception of neighborhood safety is significantly influenced by imprisonment rate. The negative and significant effects of imprisonment rate on the odds of feeling safe in all equations imply that, on average, perception of safety is likely to decrease with a country's crime problems. The percentage of the non-European population that resides in the country does not exert significant effect on perception of safety (as is demonstrated by the insignificant effect of the percentage of non-Europeans in all equations).

Inclusion of the two variables "previous exposure to crime" and "views regarding foreigners' impact on crime" among the predictors of perception of "neighborhood safety" in Model 2, does not alter the findings and conclusions obtained from the previous equation. The significant negative effect of previous exposure to crime $(b=-.60)$ in Model 2 indicates that exposure to crime is likely to decrease sense of safety. The odds of feeling safe in the neighborhood among those who were previously exposed to crime are .55 times the odds of those who were not exposed to crime. The negative and statistically significant effect of views regarding foreigners' impact on crime in Model 2 indicates that net of individual-level and country-level variables, the odds of feeling safe in a neighborhood are likely to be lower among individuals holding negative views. However, both exposure to crime and views regarding foreigners' impact on crime do not account for the relations between perceived ethnic composition of the neighborhood and sense of safety. The effects of the

16. The logic for including the interaction terms in the equation is rooted in the argument that fear of victimization is context dependent (e.g., Eitle and Taylor 2008; Quillian and Pager 2001; Stults and Baumer 2007; Thompson et al. 1992). Subsequently, it seems reasonable to test the possibility that the effects of exposure to crime and of views regarding foreigners' impact on crime of sense on safety would differ across types of neighborhoods. 
dummy variables representing perception of neighborhood ethnic composition remain significant; they hardly declined when exposure to crime and views regarding foreigners' impact on crime in Model 2 were included. That is, net of attitudes regarding foreigners' impact on crime and net of exposure to crime, sense of safety is significantly lower among residents that reported living in a neighborhood populated by ethnic minorities than among residents that reported living in a neighborhood populated by Europeans. Indeed, perceived ethnic composition of the neighborhood has significant consequences for the way residents feel about their neighborhood safety.

The insignificant interaction terms between the dummy variables representing neighborhood type and experience of crime in Model 3 suggest that, other things being equal, the change in the sense of safety due to previous experiencing a criminal act is uniform across the three types of neighborhoods. The negative interaction term between ethnic neighborhood and views regarding foreigners' impact on crime in Model 3 suggests that the impact of these views on perception of safety is significantly stronger in the ethnic neighborhoods than in either the European or the mixed neighborhoods. Moreover, the significant effect of the interaction term between ethnic neighborhood and views regarding foreigners' impact on crime and the decline in the size of the main effect of ethnic neighborhood (in Model 3 in comparison to Model 2) may imply that such views are partially responsible for the effect of perceived ethnic composition on perceived safety. The interaction term between mixed neighborhood and views regarding foreigners' impact on crime does not exert significant effect on the sense of safety; implying that the effect of these views is similar in mixed and all-European neighborhoods. ${ }^{17}$

\section{Estimating Cross-Country Variation in Neighborhood Effect on Perceived Safety}

The findings presented in the previous section reveal that net of individual's sociodemographic attributes, previous personal exposure to crime, and attitudes toward ethnic minorities, Europeans reporting residence in an ethnic neighborhood express a lower level of neighborhood safety than those reporting residence in a European neighborhood; Europeans reporting residence in ethnically mixed neighborhoods fall in between. The HGLM analysis also underscores some cross-country variation in perception of safety, suggesting that this variation is systematically associated with rate of imprisonment: the higher the rate of imprisonment (as an indicator of crime problems) the lower the level of perceived neighborhood safety.

In order to further illustrate differences in perceived neighborhood safety across types of neighborhoods across countries, we estimated separate logistic regression models for each of the 21 countries, predicting the odds of feeling safe as a function of sociodemographic characteristics (age, marital status, gender, rural versus urban residence, and insufficient income), previous exposure to crime, views regarding foreigners' impact on crime, and a series of dummy variables representing perceived type of neighborhood. In Figure 3, we display the exponentials of the coefficients (odds ratios) from these regressions for mixed and ethnic neighborhoods (the category of all-European neighborhoods is the omitted category and the coefficients for all other variables that were included in each of the 21 regression equations are not presented). The values of the coefficient exponentials (odds ratios) for ethnic and for mixed neighborhoods serve us as the respective indicators of the net differences between residents of ethnic neighborhoods and residents of all-European neighborhoods, as well as between residents of ethnically mixed neighborhoods and residents of all-European neighborhoods, in terms of the sense of safety in each country.

Although the data reveal that in all countries, the odds of feeling safe in the neighborhood are highest among residents of all-European neighborhoods, and lowest among residents of an ethnic

17. The main effect of mixed neighborhood in Model 3 is statically insignificant. We believe that this can be attributed to the high correlation between "mixed neighborhood" and the interaction terms between "mixed neighborhood" and views regarding foreigners' impact on crime. When the interaction term is not included in the equation (not presented here but available from the authors upon request) the effect of mixed neighborhood becomes highly significant. 


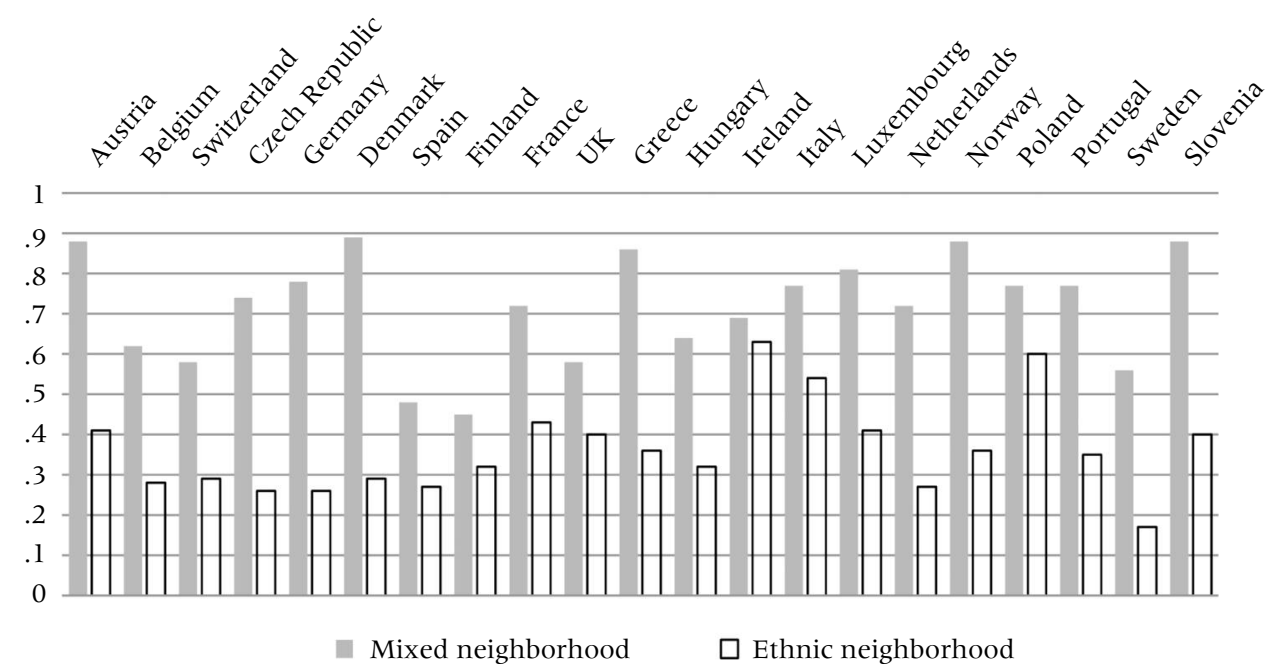

Figure 3 - Odds Ratios of Perceiving Neighborhood as Safe Compared with All-European Neighborhoods in 21 Countries

neighborhood, there are some notable variations across countries. For example, the most pronounced net differences in perceived safety between residents of ethnic neighborhoods and residents of all-European neighborhoods were found in Sweden (where the odds for residents of ethnic neighborhood feeling safe are .17 times the odds of residents of an all European neighborhood), and in Germany and the Czech Republic (where the odds of ethnic neighborhood residents of feeling safe are .26 times the odds of an all European neighborhood). The least pronounced differences were found in Ireland and in Poland. In fact, Ireland and Poland are the only two countries where the net differences between residents of ethnic neighborhoods and all-European neighborhoods are statistically insignificant. It is possible that the Irish case can be explained by high level of concerns with crime problems and lower level of concerns with the issue of immigration (Messina 2009). With regard to Poland we believe that lack of net differences in the sense of safety between respondents of ethnic and all-European neighborhoods (as well as between mixed and all-European neighborhoods) could be explained by an extremely low proportion of non-EU immigrants in the country, even in comparison to other eastern European countries. Indeed, after controlling for sociodemographic characteristics and especially for negative views regarding foreigners' impact on crime, perception of ethnic composition of the neighborhood in Poland does not affect perceived neighborhood safety.

The most pronounced net gaps between mixed neighborhoods and all-European neighborhoods are found in Finland (exp $(b)=.45)$ and in Spain (exp $(b)=.48)$. In Austria, Denmark, Greece, Italy, Luxembourg, Norway, Poland, Portugal, and Slovenia, the net differences between mixed neighborhoods and all-European neighborhoods are statistically insignificant (although the patterns are similar to the pattern observed in all other countries). In all other cases, the net differences in perceived neighborhood safety between residents of all-European neighborhoods and mixed neighborhoods are significant at conventional statistical levels.

Apparently, ethnic neighborhoods-and, to a lesser extent, mixed neighborhoods-are perceived by residents as a less safe place to live in than all-European neighborhoods, regardless of previous exposure to crime, sociodemographic attributes, and views regarding foreigners' impact on crime. Indeed, the findings imply that the perceived ethnic composition of a neighborhood has significant consequences for the image of communities and the way residents feel about their 
community-especially about its safety. Perceived neighborhood safety is likely to decline as the perceived proportion of ethnic minorities living in the community increases.

\section{Conclusions}

The primary goal of the present analysis was to examine whether the perceived ethnic composition of European neighborhoods exerts an impact on residents' sense of neighborhood safety. The findings presented by our analysis clearly reveal that the perceived ethnic composition of neighborhood is systematically associated with perceived safety. Specifically, sense of safety is lowest among Europeans who reside in neighborhoods populated mostly by ethnic minorities and highest in neighborhoods overwhelmingly populated by Europeans. Apparently, and similarly to what has been demonstrated in the United States, the perceived safety of native Europeans is associated with the perceived ethnic composition of a neighborhood. Those who perceived their neighborhood to be inhabited mostly by ethnic minorities are less likely to perceive their neighborhood as being a safe place.

The relation between perceived ethnic composition of the locality and perceived neighborhood safety remains significant even after considering neighborhood variations in sociodemographic attributes and cross-country variations in crime problems. Furthermore, this relation remains even after taking into consideration variations in previous exposure to crime and views regarding foreigners' impact on crime. As expected, sense of safety is less pronounced among those previously exposed to crime and among those holding negative views regarding foreigners' impact on crime. Likewise, sense of safety is less pronounced among physically vulnerable populations (e.g., women and the elderly) and is more pronounced among socially nonvulnerable populations (e.g., highly educated and wealthy people), as well as among people residing in rural communities. At the country level, perceived neighborhood safety is less pronounced in countries where the crime problem is higher (as measured by imprisonment rate). The percentage of nonEuropeans residing in the country was not found to affect sense of neighborhood safety. Generally speaking, therefore, the analysis reveals that net of individual-level and country-level variations, perceived neighborhood safety is least evident in places inhabited by ethnic minorities, and most pronounced in neighborhoods inhabited overwhelmingly by Europeans.

From a theoretical point of view the findings reported here lend strong support to the "visibility" or "threat" theoretical model. According to this theoretical model, an increased presence of an out-group population (i.e., immigrants and ethnic minorities) in a community is likely to increase sense of threat to prerogative, resources, and way of life of the majority and privileged population. This perceived threat not only increases negative attitudes, prejudice, and hostility toward the out-group population, but it also decreases sense of neighborhood safety. Apparently, when cast within the framework of the "threat" model, a decline in sense of neighborhood safety can be understood as a response to the increased presence (whether actual or perceived) of out-group populations in the neighborhood.

Although the findings reported by this research are consistent with the theoretical logic embodied in the "visibility" or "threat" model, they also reveal that the effect of presence of an out-group population (i.e., racial or ethnic minorities and immigrants) in the neighborhood on sense of safety (or fear of criminal victimization) extends far beyond individuals' attitudes toward minority group populations and even beyond personal experience with crime. Specifically, the findings reveal that sense of neighborhood safety is more pronounced among those who report living in an "all European neighborhood" than among those who report living in a "predominantly ethnic neighborhood" (net of attitudes toward minorities and net of personal exposure to crime). It is possible that the low sense of safety (or high fear of criminal victimization) among residents of ethnic neighborhoods stems from a general sense of distrust among the residents. Such sense of distrust could be a result of a battery of perceptions regarding social disorganization (i.e., low social cohesion, low level of social involvement, breakdown of social networks, scarcity 
of strong social ties, and low ability to realize common values) that are often associated with ethnically heterogeneous communities. Indeed, these perceptions are likely to shape cognitive maps of communities and neighborhoods and to affect the way people feel both about their place of residence and about their personal well-being.

We are aware, of course, that our central variable of interest-neighborhood ethnic composition-is based on self-reported data; as such, it measures perceived rather than actual ethnic composition. Of course, perceptions of boundaries across types of ethnic neighborhoods may vary across individuals and across countries. Nonetheless, our data show that such perceptions exert a significant impact on sense of safety above and beyond individual- and countrylevel attributes. Future research may overcome the limitation we faced by utilizing actual figures of ethnic composition of well-defined distinct neighborhoods, or districts or regions within countries and cities, and by implementing measures of crime problem at the regional or neighborhood level rather than at the country level. Such future research would provide, we hope, deeper insights into the social mechanisms underlying the relations between residential segregation and sense of neighborhood safety.

The data presented here show that the perceived ethnic composition of a neighborhood has significant consequences for the way residents feel about their personal well-being and personal safety. Indeed, perceptions of ethnic composition of neighborhoods should be viewed as a contextual variable that exerts a significant impact on the ways in which residents view their communities and especially on their perceptions of safety. These ethnically coded perceptions, in turn, become significant building blocks of cognitive maps of neighborhoods and communities. These perceptions hold even after taking into consideration variations in sociodemographic attributes of individuals, personal exposure to crime, and views regarding foreigners' impact on crime. They should be viewed, therefore, as an important part of contextual stereotyping that shapes, forms, and influences views and conceptions about neighborhoods and communities, not only in contemporary Europe but in other societies as well.

Appendix A • Definition, Percent, or Mean (Standard Deviation) of the Variables Included in the Analysis

\begin{tabular}{|c|c|c|}
\hline Variables & Definition & Percent/Mean (SD) \\
\hline \multicolumn{3}{|l|}{ Individual-level variables } \\
\hline Gender & Men $=1$ & $47.6 \%$ \\
\hline Marital status & Married = 1 & $54.6 \%$ \\
\hline Age & In years & $47.71(18.32)$ \\
\hline Type of locality & Rural = 1 & $40.2 \%$ \\
\hline Education & In years & $11.73(4.03)$ \\
\hline Subjective income & $\begin{array}{l}\text { How would you describe your household } \\
\text { income? Insufficient }=1,0=\text { sufficient }\end{array}$ & $20 \%$ \\
\hline Previous exposure to crime & $\begin{array}{l}\text { Have you or a member of your household } \\
\text { been the victim of a burglary or assault in } \\
\text { the last } 5 \text { years? Yes }=1, \text { No }=0\end{array}$ & $21.1 \%$ \\
\hline $\begin{array}{l}\text { Views regarding foreigners' } \\
\text { impact on crime }\end{array}$ & $\begin{array}{l}\text { Are [country]'s crime problems made worse } \\
\text { or better by people coming to live here } \\
\text { from other countries? crime problems } \\
\text { getting better }=0 \text {, crime problems getting } \\
\text { worse }=10\end{array}$ & $6.95(2.02)$ \\
\hline Type of current living area & $\begin{array}{l}\text { How would you describe the area where you } \\
\text { currently live? }\end{array}$ & \\
\hline All-European neighborhood & $\begin{array}{l}\text { An area where almost nobody is of a different } \\
\text { race or ethnic group from most [country] } \\
\text { people }=1\end{array}$ & $53.1 \%$ \\
\hline
\end{tabular}


Appendix A - Definition, Percent, or Mean (Standard Deviation) of the Variables Included in the Analysis (Continued)

\begin{tabular}{|c|c|c|}
\hline Variables & Definition & Percent/Mean (SD) \\
\hline Mixed neighborhood & $\begin{array}{l}\text { Some people are of a different race or ethnic } \\
\text { group from most [country] people }=1\end{array}$ & $38.1 \%$ \\
\hline Ethnic neighborhood & $\begin{array}{l}\text { Many people are of a different race or ethnic } \\
\text { group }=1\end{array}$ & $8.6 \%$ \\
\hline $\begin{array}{l}\text { Perceived neighborhood } \\
\text { safety }\end{array}$ & $\begin{array}{l}\text { How safe do you-or would you-feel } \\
\text { walking alone in this area after dark? very } \\
\text { unsafe/unsafe }=0 \text {; very safe/safe }=1\end{array}$ & $73.4 \%$ \\
\hline \multicolumn{3}{|l|}{ Contry-level variables } \\
\hline Size of minority & $\begin{array}{l}\text { Mean of percentage of non-EUR foreigners in } \\
2000 \text { and } 2001\end{array}$ & $3.21(2.47)$ \\
\hline Rate of prisoners & $\begin{array}{l}\text { Number of prisoners per } 100,000 \text { persons } \\
\text { residing in the country in } 1998 \text { and } 2001\end{array}$ & $100.08(38.85)$ \\
\hline
\end{tabular}

Sources: Eurostat 2003; OECD 2001, 2002, 2008

\section{References}

Alba, Richard, Ruben Rumbaut, and Karen Marotz. 2005. “A Distorted Nation: Perceptions of Racial/Ethnic Group Sizes and Attitudes toward Immigrants and Other Minorities." Social Forces 84:901-20.

Blalock, Hubert M. 1967. Toward a Theory of Minority Group Relations. New York: John Wiley and Sons.

$\rightarrow$ Blumer, Herbert. 1958. "Race Prejudice as a Sense of Group Position." Pacific Sociological Review 1:3-7.

Bursik, Robert and Harold Grasmick. 1993. Neighborhoods and Crime: The Dimensions of Effective Community Control. New York: Lexington Books.

Calavita, Kitty 2003. “A 'Reserve Army of Delinquents': The Criminalization and Economic Punishment of Immigrants in Spain." Punishment and Society 5: 399-413.

Castles, Stephen and Mark J. Miller. 1993. The Age of Migration: International Population Movements in the Modern World. New York: Guilford Press.

Ceobanu, Alin M. 2011. “Usual Suspects? Public Views about Immigrants' Impact on Crime in European Countries." International Journal of Comparative Sociology 52:114-31.

Chiricos, Ted, Michael Hogan, and Marc Gertz. 1997. "Racial Composition of Neighborhood and Fear of Crime." Criminology 35:107-31.

Chiricos, Ted, Renee McEntire, and Marc Gertz. 2001. "Perceived Racial and Ethnic Composition of Neighborhood and Perceived Risk of Crime." Social Problems 48:322-40.

Coenders, Marcel, Merove Gijsberts, and Peer Scheepers. 2004. “Resistance to the Presence of Immigrants and Refugees in 22 Countries" Pp. 97-120 in Nationalism and Exclusion of Migrants: Cross-National Comparisons, edited by M. Gijsberts, L. Hagendoorn, and P. Scheepers. Aldershot, UK: Ashgate.

Collins, Chiquita A. and David R.Williams. 1999. "Segregation and Mortality: The Deadly Effects of Racism." Sociological Forum 74:495-523.

Council of Europe. 2003. European Sourcebook of Crime and Criminal Justice Statistics, 2003. 2d. ed. Boom Juridische Uitgevers, Den Haag.

$\rightarrow$ De Donder, Liesbeth, Domonique Verte, and Els Messelis. 2005. "Fear of Crime and Elderly People: Key Factors that Determine Fear of Crime among Elderly People in West Flanders." Ageing International 30:363-76.

Eitle, David and John Taylor. 2008. "Are Hispanics the New 'Threat'? Minority Group Threat and Fear of Crime in Miami-Dade County." Social Science Research 37:1102-15.

European Opinion Research Group .2003. Public Safety, Exposure to Drug-Related Problems and Crime Public opinion Survey. Report prepared for The European Commission.

Eurostat. 2009. Statistics in Focus: Crime and Criminal Justice. Luxembourg: Office for Official Publications of the European Communities.

Fossett, Mark A. and K. Jill Kiecolt. 1989. “The Relative Size of Minority Populations and White Racial Attitudes." Social Science Quarterly 70:820-35. 
Gallagher, Charles A. 2003. "Miscounting Race: Exploring Whites' Misperceptions of Racial Group Size." Sociological Perspectives 46:381-96.

Gray, Emily, Jonathan Jackson, and Stephen Farrall. 2008. "Reassessing the Fear of Crime." European Journal of Criminology 5:363-80.

- 2011. "Feelings and Functions in the Fear of Crime: Applying a New Approach to Victimization Insecurity." British Journal of Criminology 5 1:75-94.

Harris, David R. 1999. “'Property Values Drop When Blacks Move In, Because . . ': Racial and Socioeconomic Determinants of Neighborhood Desirability." American Sociological Review 64:461-79.

Hartung, Halard. 2002. Eurobarometer 53: Racism, Information Society, General Services, and Food Labeling, AprilMay 2000. 3d ICPSR version. [computer file]. Brussels, Belgium: INRA (Europe) [producer]. Cologne, Germany: Zentralarchiv fur Empirische Sozialforschung/Ann Arbor, MI: Inter-University Consortium for Political and Social Research [distributors].

Hummelsheim, Dina, Helmut Hirtenlehner, Jonathan Jackson, and Dietrich Oberwittler. 201 1. "Social Insecurities and Fear of Crime: A Cross-National Study on the Impact of Welfare State Policies on CrimeRelated Anxieties." European Sociological Review 3:327-45.

Jackson, Jonathan. 2004. "Experience and Expression: Social and Cultural Significance in the Fear of Crime." British Journal of Criminology 44:946-66.

Jackson, Jonathan and Ben Bradford. 2009. "Crime, Policing, and Social Order: On the Expressive Nature of Public Confidence in Policing." British Journal of Sociology 60:493-521.

Jowell, Roger and the Central Coordinating Team. 2003. European Social Survey 2002/2003. Technical Report. London, UK: Centre for Comparative Social Surveys, City University.

Karsten, Sjoerd, Charles Felix, Guuske Ledoux, Wim Meijnen, Jaap Roeleveld, and Erik van Schooten. 2006. "Choosing Segregation or Integration? The Extent and Effects of Ethnic Segregation in Dutch Cities." Education and Urban Society 38:228-47.

Lahav, Galliya. 2004. Immigration and Politics in the New Europe. Reinventing Borders. Cambridge, UK: Cambridge University Press.

Liska, Allen E., Joseph J. Lawrence, and Andrew Sanchirico. 1982. "Fear of Crime as a Social Fact." Social Forces 60:760-70.

Logan, John R. 2006. "Variations in Immigrant Incorporation in the Neighborhoods of Amsterdam." International Journal of Urban and Regional Development 30:485-509.

Malheiros, Jorge M. and Francisco Vala. 2004. "Immigration and City Change: The Lisbon Metropolis at the Turn of the Twentieth Century." Journal of Ethnic and Migration Studies 30:1065-86.

Massey, Douglas and Nancy Denton. 1993. American Apartheid: Segregation and Making of the Underclass. Cambridge, MA: Harvard University Press.

Mayhew, Pat and Jan van Dijk. 1997. Criminal Victimisation in Eleven Industrialized Countries: Key Findings from the 1996 International Crime Victims Survey. The Hague, Netherlands: Ministry of Justice, WODC.

Mears, Daniel P. 2001. "The Immigration - Crime Nexus: Toward an Analytical Framework for Assessing and Guiding Theory, Research, and Policy." Sociological Perspectives 44:1-19.

Messina, Anthony M. 2009. "The Politics of Migration to Western Europe: Ireland in Comparative Perspective." West European Politics 32:1-25.

Moeller, Gertrude. 1989. "Fear of Criminal Victimization: The Effect of Neighborhood Racial Composition." Sociological Inquiry 59:208-21.

Musterd, Sako. 2005. "Social and Ethnic Segregation in Europe: Levels, Causes, and Effects." Journal of Urban Affairs 27:331-48.

Musterd, Sako, Wim Ostendorf, and Matthijs Breebaart. 1998. Multi-Ethnic Metropolis: Patterns and Policies. Dordrecht, Netherlands: Kluwer Academic Publishers.

Nieuwbeerta, Paul. 2004. Crime Victimization in Comparative Perspective: Results from the International Crime Victims Survey, 1989-2000. The Hague, Netherlands: Boom Legal Publishers.

Organization for Economic Co-Operation and Development (OECD). 2001. Trends in International Migration. Paris, France: OECD.

- 2002. Trends in International Migration. Paris, France: OECD. 2008. OECD Factbook 2008. Paris, France: OECD.

Ousey, Graham and Charis E. Kubrin. 2009. "Exploring the Connection between Immigration and Violent Crime Rates in U.S. Cities, 1980-2000." Social Problems 56:447-73.

Pain, Rachel. 2000. "Place, Social Relations, and the Fear of Crime: A Review." Progress in Human Geography 24:365-88. 
Peach, Ceri. 1997. "Post-War Migration to Europe: Reflux, Influx, Refuge." Social Science Quarterly 78:269-83. . 2005. "The Ghetto and the Ethnic Enclave." Pp. 31-42 in Desegregation in the City: Ghettos, Enclaves and Inequalities, edited by D. P. Varady. Albany, NY: SUNY Press.

Peterson, Ruth D. and Lawrence J. Krivo.1993. "Racial Segregation and Urban Black Homicide." Social Forces 71:1001-26.

Pettigrew, Thomas. 1998. "Reaction toward the New Minorities of Western Europe." Annual Review of Sociology 24:77-103.

Poortinga, Ype H. 1989. "Equivalence of Cross-Cultural Data. An Overview of Basic Issues." International Journal of Psychology 24:737-56.

Quillian, Lincoln. 1995. "Prejudice as a Response to Perceived Group Threat: Population Composition and Anti-Immigrant and Racial Prejudice in Europe." American Sociological Review 60:586-611.

Quillian, Lincoln and Devah Pager .2001. "Black Neighbors, Higher Crime? The Role of Racial Stereotypes in Evaluations of Neighborhood Crime." American Journal of Sociology 107:717-67.

Reese, Bobby. 2009. "Determinants of the Fear of Crime: The Combined Effects of Country-Level Crime Intensity and Individual-Level Victimization Experience." International Journal of Sociology 39:62-75.

Reif, Karlheinz and Anna Melich. 1992. Eurobarometer 30: Immigrants and Out-Groups in Western Europe, OctoberNovember 1988 [computer File]. Conducted by Fairs et Opinions, Paris. 2d ICPSR ed. Ann Arbor, MI: Inter-University Consortium for Political and Social Research [producer and distributor].

Rountree, Pamela W. and Kenneth C. Land. 1996. "Perceived Risk versus Fear of Crime: Empirical Evidence of Conceptually Distinct Reactions in Survey Source." Social Forces 74:1353-76.

Rumbaut, Ruben G. and Walter A. Ewing. 2007. The Myth of Immigrant Criminality and the Paradox of Assimilation: Incarceration Rates among Native and Foreign-Born Men. Washington, DC: Immigration Policy Center, American Immigration Law Foundation.

Scheepers, Peer, Merove Gijberts, and Marcel Coenders .2002. "Ethnic Exclusionism in European Countries: Public Opposition to Civil Rights for Legal Migrants as a Response to Perceived Threat." European Sociological Review 18:17-34.

Semyonov, Moshe, Anya Glikman, and Maria Krysan. 2007. "Europeans' Preference for Ethnic Residential Homogeneity: Cross-National Analysis of Response to Neighborhood Ethnic Composition." Social Problems 54:434-53.

Semyonov, Moshe, Rebecca Raijman, and Anastasia Gorodzeisky. 2006. "The Rise of Anti-Foreigner Sentiment in European Societies, 1988-2000." American Sociological Review 71:426-49.

- 2008. "Foreigners' Impact on European Societies: Public Views and Perceptions in a Cross-National Comparative Perspective." International Journal of Comparative Sociology 49:5-29.

Semyonov, Moshe, Rebecca Raijman, Anat Yom Tov, and Peter Schmidt. 2004. "Population Size, Perceived Threat, and Exclusion: A Multiple-Indicators Analysis of Attitudes toward Foreigners in Germany." Social Science Research 33:681-701.

Sigelman, Lee and Richard G. Niemi. 2001. "Innumeracy about Minority Populations: African Americans and Whites Compared." Public Opinion Quarterly 65:86-94.

Skogan, Wesley. 1990. Disorder and Decline: Crime and the Spiral of Decay in American Neighborhoods. New York: Free Press.

Solivetti, Luigi M. 2010. Immigration, Social Integration, and Crime. A Cross-National Approach. New York: Routledge.

Stinchcombe, Arthur, Rebecca Adams, Carol Heimer, Kim Scheppele, Tom Smith, and D. Garth Taylor. 1980. Crime and Punishment - Changing Attitudes in America. San Francisco: Jossey-Bass.

Stults, Brian J. and Eric P. Baumer. 2007. "Racial Context and Police Force Size: Evaluating the Empirical Validity of the Minority Threat Perspective." American Journal of Sociology 113:507-46.

Sutton, John R. 2004. “The Political Economy of Imprisonment in Affluent Western Democracies, 1960-1990." American Sociological Review 69:170-89.

Sutton, Robbie M. and Stephen Farrall. 2005. "Gender, Socially Desirable Responding, and the Fear of Crime. Are Women Really More Anxious about Crime?" British Journal of Criminology 45:212-24.

Taylor, Marylee C. 1998. "How White Attitudes Vary with the Race Composition of Local Populations: Numbers Count." American Sociological Review 63:512-35.

Taylor, Ralph. 1995. "The Impact of Crime on Communities." Annals, American Academy of Political and Social Scientists 539:28-45.

Thompson, Carol Y., William B. Bankston, and Roberta St. Pierre. 1992. "Parity and Disparity among Three Measures of Fear of Crime: A Research Note." Deviant Behavior 13:373-89. 
Thomson, Mark and Maurice Crul. 2007. "The Second Generation in Europe and the United States: How is the Transatlantic Debate Relevant for Further Research on the European Second Generation?" Journal of Ethnic and Migration Studies 33:1025-41.

Tonry, Michael, ed. 1997. Ethnicity, Crime, and Immigration: Comparative and Cross-National Perspectives. Chicago: University of Chicago Press.

Toseland, Ronald W. 1982. "Fear of Crime: Who is Most Vulnerable?" Journal of Criminal Justice 10:199-209.

Tseloni, Andromachi and Christina Zarafonitou. 2008. "Fear of Crime and Victimization: A Multivariate Multilevel Analysis of Competing Measurements." European Journal of Criminology 5:387-409.

van Dijk, Jan, John van Kesteren, and Paul Smit. 2008. Criminal Victimization in International Perspective: Key Findings from the 2004-2005 ICVS and EUICS. The Hague, Netherlands: Boom Legal Publishers.

van Kempen, Ronald and Jan van Weesep. 1997. "Ethnic Residential Patterns in Dutch Cities: Backgrounds, Shifts, and Consequences." Urban Studies 35:1813-33.

van Kesteren, John, Pat Mayhew, and Paul Nieuwbeerta. 2000. Criminal Victimisation in Seventeen Industrialised Countries: Key Findings from the 2000 International Crime Victims Survey. The Hague, Netherlands: Boom Legal Publishers.

Walton, Emily. 2009. "Residential Segregation and Birth Weight among Racial and Ethnic Minorities in the United States." Journal of Health and Social Behavior 50:427-42.

Whitley, Rob and Martin Prince. 2005. "Fear of Crime, Mobility, and Mental Health in Inner-City London, UK." Social Science and Medicine 61:1678-88.

Wight, Richard G., Janet R. Cummings, Arun S. Karlamangla, and Carol S. Aneshensel. 2010. “Urban Neighborhood Context and Mortality in Late Life." Journal of Aging and Health 22:197-218.

Yeager, Matthew G. 1997. "Immigrants and Criminality: A Cross-National Review." Criminal Justice Abstracts 29:143-71. 